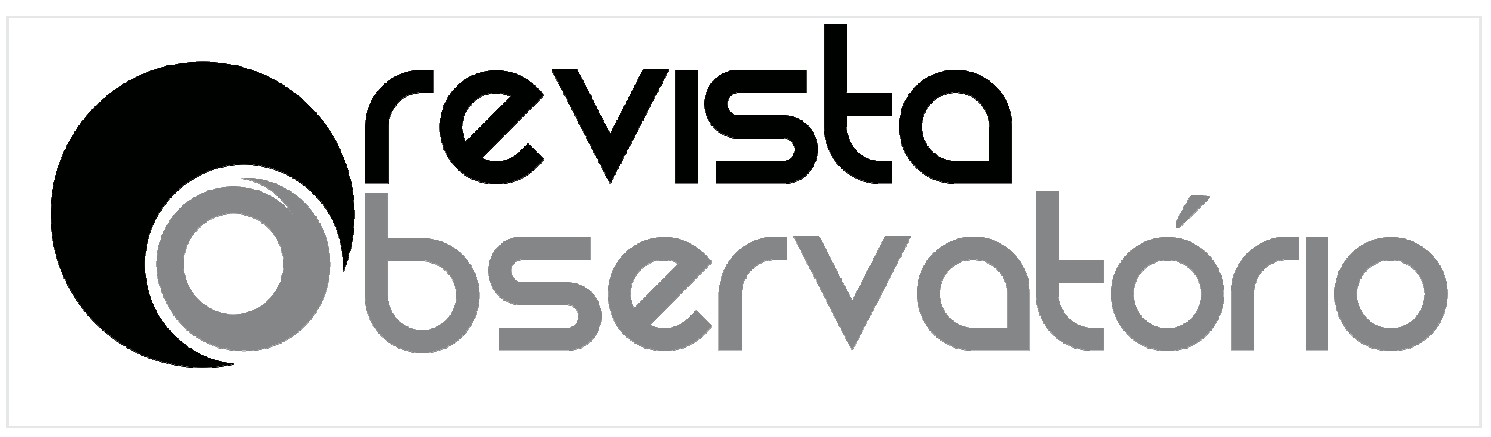

ISSN n² 2447-4266

Vol. 4, n. 2, Abril-Junho. 2018

DOI: http://dx.doi.org/10.20873/uft.2447-4266.2018v4n2p480

\section{RELEYENDO \\ ADOLESCENCIA, \\ POSMODERNIDAD Y \\ ESCUELA: \\ Veinte años después}

RELENDO A ADOLESCÊNCIA, POSMODERNIDADE E ESCOLA: vinte anos depois

RELAXING TO ADOLESCENCE, POSMODERNITY AND SCHOOL: twenty years after

Silvia Di Segni ${ }^{1,2}$

\title{
RESUMEN
}

Hace 20 años, en 1993, publicamos con Guillermo Obiols Adolescencia, posmodernidad y escuela. En ese texto analizábamos la llamada "crisis modernidad/posmodernidad", la adolescencia y la escuela media atravesadas por ella. La pregunta que guía esta relectura es: ¿qué ha cambiado en estos veinte años? Lamentablemente no está Guillermo para actualizar el análisis de época y puntos fundamentales en relación a la escuela y a la adolescencia así que ésta será, necesariamente, una relectura parcial de ese trabajo. Me resulta enriquecedor incorporar al análisis los conceptos de sociedad disciplinar y

\footnotetext{
${ }^{1}$ Doutora en Medicina por La Facultad de Medicina de la Universidad de Buenos Aires (UBA). Licenciada en Ciencias Biológicas, Facultad de Ciencias Exactas y Naturales, Universidad de Buenos Aires. Médica pela Facultad de Medicina de la Universidad de Buenos Aires. Psiquiatra, por el Ministerio de Salud Pública y Acción Social. Jefa del departamento de Filosofía y Psicología del Colegio Nacional de Buenos Aires (UBA). E-mail: silvia.disegni@gmail.com.

2 Endereço de contato com a autora (por correio): Av. Dorrego 2231, Buenos Aires, Argentina.
} 


\section{Gevisto
Observatório}

ISSN n² 2447-4266

Vol. 4, n. 2, Abril-Junho. 2018

DOI: http://dx.doi.org/10.20873/uft.2447-4266.2018v4n2p480

sociedad de control (Deleuze, 1991) y hacer hincapié en que la época que nos toca vivir ha terminado con algunas certezas.

PALABRAS CLAVE: Posmodernidad; adolescencia; escuela.

\section{RESUMO}

Há 20 anos atrás, em 1993, a autora publicou com Guillermo Obiols Adolescência, pós-modernidade e escola. Neste texto serão analisados a chamada crise da modernidade/pós-modernidade", a adolescência e o ensino médio permeados por ela. A questão norteadora desta releitura é: o que mudou em vinte anos? A autora adverte que devido a ausência de Guillermo Obiols, para atualizar o período de análise e pontos-chave em relação à escola e adolescência o texto será uma releitura parcial desse trabalho. São incorporados à análise os conceitos de sociedade disciplinar e sociedade de controle (Deleuze, 1991) para enfatizar que nos tempos atuais não existem mais algumas certezas.

PALAVRAS-CHAVE: Pós-modernidade; adolescência; escola.

\section{ABSTRACT}

Twenty years ago, in 1993, the author published with Guillermo Obiols Adolescence, postmodernity and school. In this text, the so-called crisis of modernity / postmodernity will be analyzed, "adolescence and high school permeated by it." The author points out that due to the absence of Guillermo Obiols, to update the period of analysis and key points in relation to school and adolescence, the text will be a partial re-reading of this work. there are some more certainties.

KEYWORDS: Postmodernity; adolescence; school.

Recebido em: 17.09.2017. Aceito em: 14.12.2017. Publicado em: 01.04.2018. 


\section{Crevisto}

ISSN n² 2447-4266

Vol. 4, n. 2, Abril-Junho. 2018

DOI: http://dx.doi.org/10.20873/uft.2447-4266.2018v4n2p480

Hace 20 años, en 1993, publicamos con Guillermo Obiols Adolescencia, posmodernidad y escuela. En ese texto analizábamos la llamada "crisis modernidad/posmodernidad", la adolescencia y la escuela media atravesadas por ella. La pregunta que guía esta relectura es: ¿qué ha cambiado en estos veinte años? Lamentablemente no está Guillermo para actualizar el análisis de época y puntos fundamentales en relación a la escuela y a la adolescencia así que ésta será, necesariamente, una relectura parcial de ese trabajo.

Me resulta enriquecedor incorporar al análisis los conceptos de sociedad disciplinar y sociedad de control (Deleuze, 1991) y hacer hincapié en que la época que nos toca vivir ha terminado con algunas certezas. La modernidad se construyó sobre rígidos y duraderos binarismos: varón/mujer; adulto/adolescente; europeo/salvaje; blancos/negros; religión/paganismo; ciencia/charlatanería; heterosexualidad procreativa/perversiones; normalidad/anormalidad; docente/alumno; saber académico/"saberes plebeyos" (Fernández, 2011). No se trataba de pares de términos en paridad de condiciones; uno de ellos, en general el primero, se convertía en hegemónico y el otro era perseguido, sometido, desautorizado, aniquilado, ubicado en el lugar de "fondo" sobre el cual resaltar la "figura" autorizada. No se puede decir que la creación de binarismos y la hegemonía de uno de sus términos sea cosa del pasado, sólo que se ha producido cierta fractura que ha permitido la visibilización de la diversidad que esos binarismos ocultaban. Así se autorizaron: la "cultura adolescente", los saberes feministas, los pueblos originarios, los saberes de colectivos LGBTI, las necesidades y saberes de personas con discapacidades, entre otros. De todos ellos la cultura adolescente fue la que más sufrió la captación por el mercado que le ofreció bienes y servicios 


\section{Gevisto
Observatório}

ISSN n² 2447-4266

Vol. 4, n. 2, Abril-Junho. 2018

DOI: http://dx.doi.org/10.20873/uft.2447-4266.2018v4n2p480

incalculables a cambio de hacerle perder su rebeldía original. En ese proceso la adolescencia fue convertida en modelo social: allí donde por milenios había reinado el adulto (en particular el varón adulto) ahora estarían los y las adolescentes. Estos procesos atravesaron con fuerza a la escuela; la "cultura adolescente" compite con ella y la pérdida de autoridad tanto de la institución escolar como de las personas adultas que la pueblan han producido cambios importantes que resultan en un menor interés de los y las adolescentes por lo que la escuela enseña y la pérdida de aquel respeto automático al que estaban acostumbrados los y las docentes de otras épocas.

Sabemos que la adolescencia y la escuela media nacieron al mismo tiempo, permitiendo la escuela a los jóvenes (por entonces sólo varones) la posibilidad de una moratoria vital dedicada a la formación antes de incorporarse al mundo del trabajo y cumplir con el pago de la deuda adquirida con padres y madres por haber nacido y haber recibido una crianza. Los estudiantes que accedieran a la novedosa escuela media en los siglos XVII y XVIII vivirían una situación privilegiada: un período en el cual sólo se les exigiría educarse. Esto les daría herramientas para conseguir autonomía que no dependiera de la riqueza o de los saberes familiares $y$, también, la posibilidad de establecer fuertes vínculos entre pares que podían competir con los familiares. La tensión familia-escuela nace desde el origen de la institución.

Si estos fueron los comienzos habrá que llegar a la segunda mitad del siglo XX para que la adolescencia adquiera cierto poder y aparezca en el escenario social rechazando la educación burguesa dominante. Es bueno recordar que niños, niñas y adolescentes adquierieron derechos tardíamente, con la Declaración de los derechos del Niño que las Naciones Unidas aprueban apenas en 1959. Para entonces el mercado ya había detectado que la 


\section{Gevisto
Observatório}

ISSN n² 2447-4266

Vol. 4, n. 2, Abril-Junho. 2018

DOI: http://dx.doi.org/10.20873/uft.2447-4266.2018v4n2p480

adolescencia era un objetivo valioso al cual ofrecer bienes y servicios hasta entonces casi inexistentes. Jóvenes rebeldes de sectores medios se adueñaron de ropas (jean, zapatillas, camperas), vehículos (motocicletas) y música (rock) propias, en los EEUU que creó la imagen joven por excelencia, de los sectores populares. Fue una suerte de "proletarización" de la juventud que también asumió formas más libres de vivir la sexualidad y cierto nomadismo popularizado por la gran novela de la época, En el camino de Jack Kerouac. Por razones socioeconómicas y culturales, estas características de vestimenta y de forma de vida eran más frecuentes en sectores populares que en la burguesía donde eran desacreditadas considerándolas "bohemias" lo que por entonces era sinónimo de "marginales". A medida que el mercado logra captar a los y las jóvenes impone sus leyes y aquellos bienes, originalmente populares, pasarán a tener en algunas marcas precios exorbitantes lo que hará que jóvenes de sectores de menores recursos hagan lo imposible para adquirirlos porque tenerlos será sinónimo de pertenecer a la "juventud dorada".

Ubicar como modelo social a la adolescencia llevó a la adolescentización de la sociedad y a concomitantes cambios en los adultos. Al comienzo de este proceso, en los años 50 y 60 del siglo XX los y las adolescentes comenzaron a comprar lo que se les ofrecía con dinero conseguido con su propio trabajo. A medida que el mercado impuso la moda adolescente y toda suerte de bienes y servicios la deuda que, supuestamente, se contraía con padres y madres pasó a constituirse en un crédito que ni siquiera depende del nivel económico de la familia ya que aún en sectores populares y marginales se gasta lo que no se tiene para comprar lo que hijos e hijas deseen. El modelo social adolescente actuó como un imán fortísimo subsumiendo otras etapas tradicionales de la vida. La infancia se recortó para entrar lo antes posible en la adolescencia; la 


\section{Orevisto}

ISSN n² 2447-4266

Vol. 4, n. 2, Abril-Junho. 2018

DOI: http://dx.doi.org/10.20873/uft.2447-4266.2018v4n2p480

adultez se licuó mientras las personas cronológicamente maduras intentan parecer adolescentes el mayor tiempo posible antes de caer en la vejez desestimada. Se podrá determinar cuando comience fisiológicamente la adolescencia porque sigue ligada a un proceso hormonal, la pubertad, pero ya niños y niñas de jardín de infantes se vestirán como adolescentes, seguirán a bandas de música, tendrán viajes de egreso y cualquier otro bien o servicio que pueda ponerse en sus manos. Por el otro lado cada vez es más difícil determinar cuando termina la adolescencia ya que se puede mantener muchos años un aspecto adolescente con ayudas varias y también porque se puede tener un modo de vida adolescente, y ganar dinero en el campo de la cultura adolescente, durante toda la vida. Ese modo de vida circula en torno a los servicios dedicados a la adolescencia y la juventud: lugares de encuentro con todas las actividades ligadas a ellos: dj, bandas de música, bartender, viajes de egreso de las escuelas, entre otras. Estas actividades se desarrollan en el espacio de tiempo que se colonizó a tal efecto: la noche, en clara oposición al día tradicionalmente ocupado por la escuela y el "verdadero" trabajo. La cultura adolescente nació enfrentando la sociedad disciplinar y la represión que la sostenía. Ante ella oponía el descontrol sintetizado en el ideal beat: sexo, drogas y rock'n roll. El exceso de control había mostrado que puede enfermar y matar, el descontrol también lo demostró. En nuestra época tenemos adolescentes en riesgo por ambos extremos pero algo que me parece importante tomar en cuenta es que hoy en día hay adultos muy dispuestos a promover el descontrol adolescente porque ganan mucho dinero con él vendiendo alcohol y otras drogas en espacios supuestamente "libres de personas adultas". Esto último no es cierto ya que los espacios de socialización adolescente están perfectamente controlados no por criterios de seguridad sino 


\section{Grevisto}

ISSN n² 2447-4266

Vol. 4, n. 2, Abril-Junho. 2018

DOI: http://dx.doi.org/10.20873/uft.2447-4266.2018v4n2p480

de admisión de aquellos y aquellas que respondan al modelo adolescente buscado. $Y$ ese tipo de control puede ejercerse con enorme agresividad.

Hasta aquí no he mencionado la irrupción de los teléfonos móviles y dispositivos electrónicos de comunicación y juego que crecieron exponencialmente en las últimas décadas. Hace veinte años las computadoras eran caras y fijas, los teléfonos móviles caros y poco comunes; hoy encontramos que niños y niñas de educación preescolar llevan teléfonos a sus jardines de infantes justificados por razones de "seguridad" (supuestos abusos posibles de parte de sus docentes, acosos de sus compañeras/os) aunque tenerlos pueda exponerles a un robo. $Y$ que, quienes pueden hacerlo, reciben tabletas en la escuela primaria donde tienen acceso a un número infinito de juegos. El mundo del juego ha adquirido tanta autonomía del mundo adulto que para algunas personas adultas entender qué juegan sus jóvenes familiares o estudiantes es complejo o imposible. Estos juegos nuevos no imitan la vida de personas adultas como lo hacían las herramientas, las cocinitas, las muñecas, los automóviles sino que conforman un mundo totalmente apartado del mundo adulto. Por otra parte tienen como particularidad que, a falta de pares reales para jugarlos, se encuentran pares virtuales en red. Se trata de otra lógica tanto de los juegos en sí como de su dinámica social y suele dejarse a niños, niñas y adolescentes con ellos sin mayor idea de qué son o cómo funcionan mientras esas mismas personas adultas están dispuestas a desconfiar de sus docentes o cualquier otra persona que se vincule con sus hijos e hijas. Resulta obvio que las nuevas tecnologías, así como los libros o la televisión, no son ni buenas ni malas en sí, todo depende de cómo se usen y en manos de quien se pongan. Su mejor uso depende de haber podido desarrollar en la infancia, de la mano de la familia y la escuela, otros intereses y pensamiento crítico. La escuela, instituida 


\section{Gevisto
Observatório}

ISSN n² 2447-4266

Vol. 4, n. 2, Abril-Junho. 2018

DOI: http://dx.doi.org/10.20873/uft.2447-4266.2018v4n2p480

alrededor del libro como herramienta, trabaja eligiendo algunos libros y, también, proporcionando elementos para discriminar cuáles leer, es decir que no parte de la premisa que todo libro es bueno sólo por serlo sino que da elementos para valorar y elegir. Si la escuela y la familia hicieran lo necesario para desarrollar el amor al deporte, la lectura, la ciencia, las artes y el trabajo comunitario como alternativa al hacerse adoptar por la tecnología la situación podría equilibrarse. También se equilibraría si las personas adultas no abusaran de los "chupetes" electrónicos para evitar entretener o enseñar a las generaciones jóvenes. Y no siempre la escuela, a pesar de ser heredera del Iluminismo, dedica suficiente esfuerzo a desarrollar el pensamiento crítico que se vuelve imprescindible ante el despliegue de la información/diversión disponible. Aquí no se trata de caer en otro binarismo en términos de "bueno" o "malo" sino de dar herramientas para navegar el mundo virtual encontrando toda su riqueza y pudiendo discriminar aquello que pueda ser empobrecedor, riesgoso o no adecuado a una etapa de la vida. A veces no se estimula el pensamiento crítico para promover el sometimiento pero también para evitar someterse a él, ya que una vez desarrollado puede caer con sus críticas también sobre quien lo enseña. $Y$ también implica proporcionar una herramienta para construir autonomía, algo muy diferente a convertirse en proveedor/a a muy largo plazo de todo bien y servicio de hijas e hijos que quedan en un lugar de privilegiado control. ¿Por qué hoy tantas personas adultas optan por esta segunda opción y sostienen económicamente durante varias décadas a su hijos e hijas? En parte porque ser quien provee propone un papel muy gratificante para el narcisismo; también porque, mientras hijos e hijas parecen no crecer, las personas adultas ilusionan no envejecer. Está claro que, en la competencia con otras familias, los bienes y servicios proporcionados a hijos e hijas se han convertido, así como el automóvil o la ropa, en una clara muestra del poderío 


\section{Gevisto
Observatório}

ISSN n² 2447-4266

Vol. 4, n. 2, Abril-Junho. 2018

DOI: http://dx.doi.org/10.20873/uft.2447-4266.2018v4n2p480

económico familiar. Por su parte, la generación joven que quiera independizarse tendrá que renunciar a una serie de comodidades difíciles de conseguir, de manera que prolongar la convivencia suele ser una solución básicamente "cómoda".

La tecnología no siempre está a disposición de la diversión y la socialización de niños, niñas y adolescentes. La sociedad de control no vigila directamente ni castiga como hacía la sociedad disciplinar sino que promueve el miedo para controlarnos. Más allá de un crecimiento real posible de actos delictivos en las grandes ciudades (en Buenos Aires lo que ha crecido son los robos pero mantiene una tasa baja de críminalidad) la publicidad que les dan los medios masivos genera un clima de miedo constante. La industria que vende bienes y servicios que brindan "seguridad" ha crecido de manera impensada. Tal como los señaló Stolkiner (Stolkiner, 1994), hemos pasado de marginales encerrados a personas temerosas encerradas en casas enrejadas 0 barrios cerrados que dejan libre la calle para uso de delincuentes. El miedo se utiliza también para controlar adolescentes, sobre todo mujeres, a quienes se les exige un constante envío de mensajes notificando cuando salen, cuando llegan, donde están, con quien, matrícula del taxi en el que se traslada. Se viola la privacidad de sus dispositivos electrónicos en busca de información y también se utilizan programas de localización geográfica en sus teléfonos ante la supuesta posibilidad de secuestros. Lo cierto es que mientras niños y niñas de sectores populares y marginales pueden sufrir un exceso de "calle" los de sectores medios y altos no tiene experiencia ni de caminar por ellas, se los cría en burbujas artificiales. Obviamente, la calle tan temida por las familias se ha convertido en el lugar preferido de muchos y muchas adolescentes que, sin 


\section{Oevisto}

ISSN n² 2447-4266

Vol. 4, n. 2, Abril-Junho. 2018

DOI: http://dx.doi.org/10.20873/uft.2447-4266.2018v4n2p480

importar sus medios económicos, "paran" en alguna esquina o plaza donde se encuentran con pares.

Aunque algunas personas adultas se identifican claramente con la adolescencia constituyendo un tipo adulto-adolescente toda su vida, hoy es casi imposible encontrar en el Occidente influido por la cultura estadounidense una subjetividad adulta que no sea atravesada en alguna medida por la cultura adolescente. Una de las ilusiones parentales de la época es creer que se puede, y sería bueno hacerlo, ubicarse como "amigo/a" de hijos e hijas o de los y las estudiantes. Es cierto que se puede establecer una comunicación intergeneracional mucho mejor que la de las generaciones anteriores, que era casi inexistente, pero lo que no se puede esperar es que la generación adulta pierda de vista las diferencias que crea su responsabilidad en relación a menores a cargo. Algunas personas adultas intentan establecer un intercambio comunicacional contando intimidades de la propia vida o compartiendo alcohol y marihuana, algo que los y las adolescentes suelen rechazar mientras intentan lograr el objetivo de separarse de la generación anterior enviando un mensaje claro, a veces a los gritos: "ustedes son personas adultas, yo no, ocupen su papel", algo que el narcisismo adulto de hoy tolera mal. Ocupar el lugar adulto supone satisfacciones pero también sacrificios y frustraciones. En este sentido es importante que existe la posibilidad de no tener hijos ni hijas, ni ser docente, pero, si se lo hace, no puede evitarse la responsabilidad que conlleva. Optar por convertirse en pares o dejarles huérfanas/os de figuras adultas es un camino menos exigente pero que termina mal para los y las más jóvenes.

En una época globalizada en la cual fama, dinero y poder serían los grandes bienes para lograr felicidad, las familias compiten entre sí y, no pocas veces lo hacen a través de sus hijas e hijos. Existen escuelas públicas donde 


\section{Orevisto}

ISSN n² 2447-4266

Vol. 4, n. 2, Abril-Junho. 2018

DOI: http://dx.doi.org/10.20873/uft.2447-4266.2018v4n2p480

todavía conviven estudiantes de sectores sociales diferentes pero también hay muchas instituciones privadas que nuclean estudiantes de población más homogénea. Todas están atravesadas por el consumo que, en algunos casos, se mostrará de manera muy evidente $y$, en otros, a través de detalles significativos sólo para quien conozca todo sobre marcas y modelos. El consumismo en la escuela y en el barrio aparece como potenciador de envidias y competencias que, no pocas veces, derivan en discriminación, acoso y agresiones físicas. Otro de sus efectos, lamentable, es promover la incapacidad para tolerar frustraciones. Niños, niñas y adolescentes cuyos deseos han sido constantemente satisfechos no están capacitados/as para soportar que algo no ocurra como desean o no consigan logros que no se compran en el mercado. Esto merece alguna digresión.

Los seres humanos nacemos inmaduros para la vida y esa inmadurez incluye la incapacidad de tolerar cualquier frustración. Uno de los puntos esenciales, poco atendido últimamente, tanto por la crianza como por la educación, es el aprender a hacerlo. La sociedad disciplinar era básicamente frustrante para niños, niñas y adolescentes en un grado que producía personas violentas o sometidas. Nuestra época optó por evitar a las generaciones más jóvenes frustraciones que pensaba, con razón, que podían ser traumatizantes pero no contó con un mercado que se sumó ofreciendo toda suerte de bienes y servicios tendientes a evitar casi cualquier frustración de efectos nefastos. Si bien esto es más cierto en los sectores medios y altos también en los sectores populares también existe este peligro porque la industria genera bienes y servicios de todos los precios. De hecho es muy difícil determinar hoy lo que se solían llamar "necesidades básicas" dado que no han hecho más que aumentar. 


\section{Gevisto
Observatório}

ISSN n² 2447-4266

Vol. 4, n. 2, Abril-Junho. 2018

DOI: http://dx.doi.org/10.20873/uft.2447-4266.2018v4n2p480

La tolerancia a las frustraciones la ejercitan los "no" adecuados para cada edad que los seres humanos encontremos en nuestros caminos. Esos "no" irán marcando los límites que cada uno/a necesita para vivir. Resulta imprescindible aquí definir qué entiendo por "límite" porque hay quienes piensan que se trata de castigar o frustrar agresivamente y quienes, en otro extremo, temen que sean solamente una manifestación de autoritarismo. Entiendo por "límite" que todo ser humano sea capaz de conocer qué puede hacer sin ponerse en riesgo o exigirse más de lo posible, es decir reconocer las propias limitaciones y que para vivir en sociedad debe saber cuando puede satisfacer sus deseos y cuando debe ceder lugar a los deseos de quienes le rodean. Esto requiere tolerancia a la frustración. Parece sencillo, tanto que se supuso que la educación preescolar podía lograrlo; hoy, parece casi imposible de instalar. Y esto no sólo dificulta la convivencia sino que impide el normal proceso de aprendizaje dado que durante el mismo hay que tolerar fracasos imprescindibles. En la adolescencia, la falta de esta capacidad hace irrupción a veces de manera dramática dado que las drogas son el escape perfecto ante cualquier frustración; también emerge en conductas auto y heterodestructivas (abandono de estudios, parejas, trabajos por el menor inconveniente; agresiones a quienes consiguen lo que ellas/ellos no).

Los medios masivos tematizan constantemente sobre dos aspectos de la agresividad que aparece entre adolescentes, uno es la emergencia de agresividad física entre mujeres; el otro, el acoso en las redes sociales. Cuando las peleas, a menudo brutales, ser producían más frecuentemente entre varones, se las naturalizaba, incluso se esperaba que ocurrieran como un camino necesario hacia la masculinidad. Si ocurren entre mujeres son igualmente lamentables pero, además, llegan a los medios. La llegada a los medios en una 


\section{Qrevisto}

ISSN n² 2447-4266

Vol. 4, n. 2, Abril-Junho. 2018

DOI: http://dx.doi.org/10.20873/uft.2447-4266.2018v4n2p480

sociedad que espera conseguir sus 15 minutos de fama no hace más que promover este tipo de conductas. Hoy se planean humillaciones a docentes o peleas entre pares para filmarlas y subirlas a la red como modo de acercarse a esa fama. El acoso tampoco es un fenómeno novedoso, lo novedoso es haberlo llamado bullying y que adquiera una difusión masiva a través de las redes sociales. Nuevamente, a pesar de lo complejos que puedan ser este tipo de comportamientos no se puede dejar de lado el efecto que ejerce sobre ellos la competencia dentro del consumismo y la incapacidad de tolerar que otros y otras tengan algunas cualidades como la belleza considerada ideal, más riqueza o, por el contrario, se les ataque por no responder a la representación exitosa como objeto de todas las burlas. No pocas veces quienes sufren este tipo de acoso no encuentran apoyo de la generación adulta y no recurren a ella. Lo mismo pasa ante los abusos de pedófilos que encuentran a niñas muy solas ante las pantallas.

Se suele hacer hincapié en el consumo de drogas en la adolescencia, alcohol en primer término, mientras la industria y la publicidad manejadas por personas adultas banaliza la cerveza ubicándola casi como una bebida gaseosa inocua y logrando así un altísimo consumo. Lo que no se visualiza con igual preocupación es el consumo de fármacos indicados por profesionales y aceptados por las familias. La industria farmacológica amplió su base hace pocas décadas a niños, niñas y adolescentes, algo justificable sólo en casos excepcionales. Hemos asistido a la medicación masiva del engañoso diagnóstico de ADD (Trastorno de Atención Dispersa con o sin Hiperactividad) endilgado a quienes quizás, simplemente, no habían introyectado la menor noción de límite; vemos adolescentes considerados portadores de depresiones sin tomar en cuenta que algunos procesos depresivos no medicables son 


\section{Oevisto}

ISSN n² 2447-4266

Vol. 4, n. 2, Abril-Junho. 2018

DOI: http://dx.doi.org/10.20873/uft.2447-4266.2018v4n2p480

normales en la adolescencia; adolescentes diagnosticadas/os con cuadros de ansiedad, TOC, trastornos del sueño, esquizofrenias llamada latentes (i) pero ya medicables. Las familias que prefieren medicar a ocuparse de sus hijos/as son la contrapartida necesaria de una medicina que pretende ser expeditiva y una industria farmacológica que básicamente piensa en vender. Todo niño o niña que no hubiera aprendido a quedarse más o menos tranquila/o el tiempo necesario para la clase escolar será medicado/a. La invención de diagnósticos para vender medicamentos es una antigua y lamentable práctica. $Y$, en particular, aquellos que tienden a controlar manifestaciones normales de la adolescencia. Un antecedente dedicado sobre todo a los adolescentes varones surgió en el siglo XVIII cuando dos médicos, los doctores Marten y Tissot, en sucesivos escritos "inventaron" la masturbación como práctica a la que le atribuían la etiología del deterioro físico e intelectual, la gonorrea, la epilepsia, la infertilidad, la locura y cualquier otro mal de origen desconocido por entonces. No parece casual que esto coincidiera con la escuela media, los internados en los cuales los jóvenes varones estaban lejos de la familia y convivían entre ellos adquiriendo cierta autonomía y tomando conciencia del poder que podían adquirir. De hecho Tissot proponía:

Vigilad a los jóvenes, no les dejéis solos ni de día ni de noche; al menos, dormid con ellos en su propio cuarto pues cuando hayan contraído este hábito (el que más funestamente puede dominar a un joven) sufrirán hasta la muerte sus tristes efectos y tendrán siempre enervado su cuerpo y su corazón (Tissot, 2003:139)

La sociedad disciplinar vigilaba y castigaba para controlar y someter a los jóvenes; la sociedad de control medica a niños, niñas y adolescentes con el mismo fin. La escuela, hija de la sociedad disciplinar fue concebida para educar a personas "normales" y normalizar conductas de quienes se alejaran de las 


\section{Orevisto}

ISSN n² 2447-4266

Vol. 4, n. 2, Abril-Junho. 2018

DOI: http://dx.doi.org/10.20873/uft.2447-4266.2018v4n2p480

representaciones hegemónicas transmitiendo conocimientos considerados adecuados, promoviendo habilidades adaptativas a una sociedad considerada ideal, formando en valores que no pusieran en riesgo a esa sociedad. Todo lo anormal, perverso o monstruoso debería quedar fuera de ella y dentro de esas categorías quedarían entrampadas todas las personas que fueron recortadas del ideal "normal" y que hoy aparecen en escena y reclaman sus derechos. Aquel niño, niña o adolescente que tuviera una discapacidad o se le considerara portador de alguna anormalidad debería ir a una escuela diferente, especial o ser expulsado. $Y$ todo/a docente que manifestara alguna discapacidad o una sexualidad que no respondiera a la heteronormatividad no tendría acceso a la escuela. En escuelas religiosas sostener la "normalidad" llevó a expulsar a docentes que se hubieran divorciado, jóvenes embarazadas (no sus parejas); a no admitir a hijos e hijas de divorciados; expulsar y/o proponer tratamientos para personas gay y lesbianas. La realidad ha producido algunos cambios en estas conductas, pero sobreviven. Hoy la escuela argentina tiene una ley de Educación Sexual Integral (Ley de Educación Sexual Integral 26150 (10/2006) con sus Lineamientos curriculares para la Educación Sexual Integral (ESI)(5/ 2008) que ha incorporado la igualdad de oportunidades para las mujeres pero mantiene todavía una fuerte deuda con las personas LGBTI. De todos modos la realidad atraviesa la escuela y hace llegar a ella familias homoparentales, docentes y estudiantes de diferentes sexualidades y géneros. Las leyes de matrimonio igualitario (Ley de matrimonio igualitario 26618 (7/ 2010) y de identidad de género Ley de identidad de género 26743 (5/2012) lo han habilitado. La escuela debe dar rápidamente respuesta a situaciones que nunca contempló o, por el contrario, que se ocupó cuidadosamente de expulsar. Todas las disciplinas deben repensarse desde la diversidad sexual y de género visibilizando a quienes por ser mujeres o tener otras sexualidades fueron 


\section{Gevisto
Ooservatório}

ISSN n² 2447-4266

Vol. 4, n. 2, Abril-Junho. 2018

DOI: http://dx.doi.org/10.20873/uft.2447-4266.2018v4n2p480

eliminados/as u ocultados/as. Ciencias como la biología exigen revisión dado que las características intersexuales aparecen naturalmente $y$ ha sido la medicina la que ha encerrado con todo el poder de la cirugía a toda la población en el binarismo varón-mujer. Las leyes pueden ser muy progresistas pero no cambian automáticamente las mentalidades, en ese proceso familias, escuelas y medios masivos deben ocupar su lugar. A pesar de ellas, colectivos LGBTI denuncian constantemente abusos, discriminación y violencia así como la invisibilidad de sus propias vidas en la cultura escolar. Personas gay, lesbianas y trans relatan que no han utilizado los baños durante toda su escolaridad por no sentirse reconocidas/os en "varones" y "mujeres" o porque sus pares les hacían sentir, claramente y repitiendo prejuicios familiares, mal recibidos/as en ellos.

He mencionado la pérdida de autoridad de las personas adultas hoy $\mathrm{y}$, en particular, de progenitores y docentes. El mero hecho de llegar a cierta edad o de tener un título habilitante para la docencia lograba tradicionalmente que las personas adultas adquirieran autoridad aunque esta no tuviera bases sólidas. Esto era más fácil para los varones que para las mujeres pero algo de esa autoridad también llegaba a manos femeninas. $Y$, una vez conseguida, se mantenía para siempre si no se cometía algún error serio. Todo el colectivo adulto la sostenía: si un menor no reconocía esa autoridad cualquier persona adulta podía recriminarle no hacerlo, y lo hacía en el espacio familiar, en el escolar o por la calle. En la medida en que se fracturó la Autoridad del varón adulto ésta cambió sus características. Hoy no ha desaparecido pero se requiere esfuerzo para obtnerla y no llega a tener las dimensiones de otras épocas excepto en algunas figuras notables. Hoy, la autoridad adulta se construye cada día y la docente, en cada clase. 


\section{Orevisto}

ISSN n² 2447-4266

Vol. 4, n. 2, Abril-Junho. 2018

DOI: http://dx.doi.org/10.20873/uft.2447-4266.2018v4n2p480

La escuela, como institución, ha perdido autoridad por diversas razones. Porque al perder valor social las personas adultas, también lo perdieron los y las docentes; porque, por suerte, la educación ha continuado masificándose pero lo masivo no tiene la autoridad que tiene lo exclusivo; porque si bien sigue siendo imprescindible pasar por la escuela media para acceder al mercado de trabajo, cada vez es más difícil que la escuela asegure el éxito económico y, además, ese éxito económico como lo muestra la difusión de las figuras más ricas del planeta, hoy no tiene límite. Hasta mediados del siglo XX, una maestra, un técnico o un perito mercantil tenían habilitadas buenas perspectivas laborales sólo con esos títulos y, consecuentemente, una autoridad consagrada. Lo que ya señalábamos hace veinte años era un proceso de "inflación" que se notaba en la educación y que llevaba a que, por entonces, ni siquiera estudios cuaternarios dieran seguridad de una salida laboral. Esto no ha hecho más que incrementarse con cursos de doctorado y posdoctorado que parecen imprescindibles casi para comenzar una carrera académica. Al mismo tiempo también ha seguido creciendo llamativamente la diversidad de carreras y tecnicaturas que se renuevan día a día y compiten con otra variedad de propuestas que surgen fuera del ámbito académico lo que dificulta la elección de carrera en la adolescencia. También vemos personas adultas abandonando títulos universitarios y cambiando totalmente de rumbo, del mismo modo que se cambia de pareja o de trabajo. Los títulos universitarios han ido perdiendo valor incluso para quienes hicieron grandes esfuerzos por conseguirlos. Por otra parte, un mundo en permanente cambio hace que sea casi imposible predecir qué estudios permitirán salida laboral a futuro, incluso cuando se trate de un futuro corto como el tiempo que demora una carrera. 


\section{Grevisto
Observatório}

ISSN n² 2447-4266

Vol. 4, n. 2, Abril-Junho. 2018

DOI: http://dx.doi.org/10.20873/uft.2447-4266.2018v4n2p480

Para poder llevar adecuadamente adelante la tarea, la escuela no sólo debe incluir aspectos valiosos de la cultura adolescente sino de toda la diversidad que había dejado fuera. Toda diversidad aumenta la riqueza y contribuye a que los contenidos a transmitir, las habilidades a desarrollar y los valores a formar adquieran vida. De otro modo se reducen a una retórica que no convence ni a los/las docentes. En este sentido la escuela debe aceptar dejar la normalización y prepararse para incorporar la diversidad. Podríamos preguntarnos ¿qué valoran hoy los/las estudiantes de sus docentes? ¿Qué hace que los/las autoricen para ejercer la docencia? La idealización de las personas adultas significativas sigue actuando en la adolescencia aún cuando sea difícil identificarla bajo actitudes que pueden mostrar todo lo contrario. Los y las docentes son figuras, como padres y madres, pasibles de identificación, posibles de imitar, modelos cercanos muy válidos. Y serán autorizados/as cuando demuestren ocupar el lugar adulto sosteniendo límites y tomando la responsabilidad de su tarea; mientras intenten la mejor comunicación posible; en la medida en que conozcan profundamente lo que quieren transmitir y lo relacionen con la vida cotidiana y, lo más importante, mientras sientan pasión por la docencia. Esto último no se aprende, a veces se ha tenido y se pierde; en esos casos será mejor dedicarse a otra tarea.

\section{Referências}

BACHILLERATO Popular Trans Mocha Celis, http://www.mochacelis.com.ar/ (consultado el 3/03/2014)

BETTELHEIM, B. (1978); en Winter - Nuss, Adolescencia y aprendizaje, Buenos Aires, Paidós. 


\section{Crevisto}

ISSN n² 2447-4266

Vol. 4, n. 2, Abril-Junho. 2018

DOI: http://dx.doi.org/10.20873/uft.2447-4266.2018v4n2p480

DELEUZE, G.; (1991) "Posdata sobre las sociedades de control", en Ferrer, Ch. (comp.) El lenguaje literario, Nordan, Montevideo.

DI SEGNI, S.; (2006); Adultos en crisis/Jóvenes a la deriva, Buenos Aires, Noveduc.

DI SEGNI, S.; (2013); Sexualidades. Tensiones entre la psiquiatría y los colectivos militantes, Bs. As., Fondo de Cultura Económica.

ERIKSON. E., (1968), Identidad, juventud y crisis, Bs. As, Paidós.

FERNÁNDEZ, A.M.; (2011) "Hacia los Estudios Transdisciplinarios de la Subjetividad. (Reformulaciones académico- políticas de la diferencia)", Revista Investigaciones en Psicología, Bs. As., Instituto de Investigaciones de la Facultad de Psicología (UBA), año 16, No 1, PP.: 61-82

FERNÁNDEZ, A.M. (2009) Diferencias desigualadas, Rev. Nómadas, No. 30. Univ. Central de Colombia, http://www.scielo.org.co/pdf/noma/n30/n30a3.pdf (visto en 4/2014)

PROGRAMA Nacional de Educación Sexual Integral, (2010); Educación Sexual Integral para la Educación Secundaria. Contenidos y propuestas para el aula, Buenos Aires, Ministerio de Educación.

PROGRAMA Nacional de Educación Sexual Integral, (2012); Educación Sexual Integral para la Educación Secundaria II. Contenidos y propuestas para el aula, Buenos Aires, Ministerio de Educación.

LEY de Matrimonio Igualitario 26618 (07/2010) http://www.infoleg. gob.ar/infoleglnternet /anexos/165000-169999/169608/norma.htm (consultado el 02/02/13)

LEY de identidad de género $26743 \quad$ (5/ 2012) http://www.infoleg.gob.ar/infoleglnternet/

OBIOLS, G.; Di Segni, S.; (2006), Adolescencia, posmodernidad y escuela, Buenos Aires, Noveduc.

STOKINER, A.; (1994),"Tiempos "posmodernos" : ajuste y salud mental", en Políticas en Salud Mental, comp. Osvaldo Saidon y Pablo Troianovski, Lugar Editorial, Buenos Aires, 


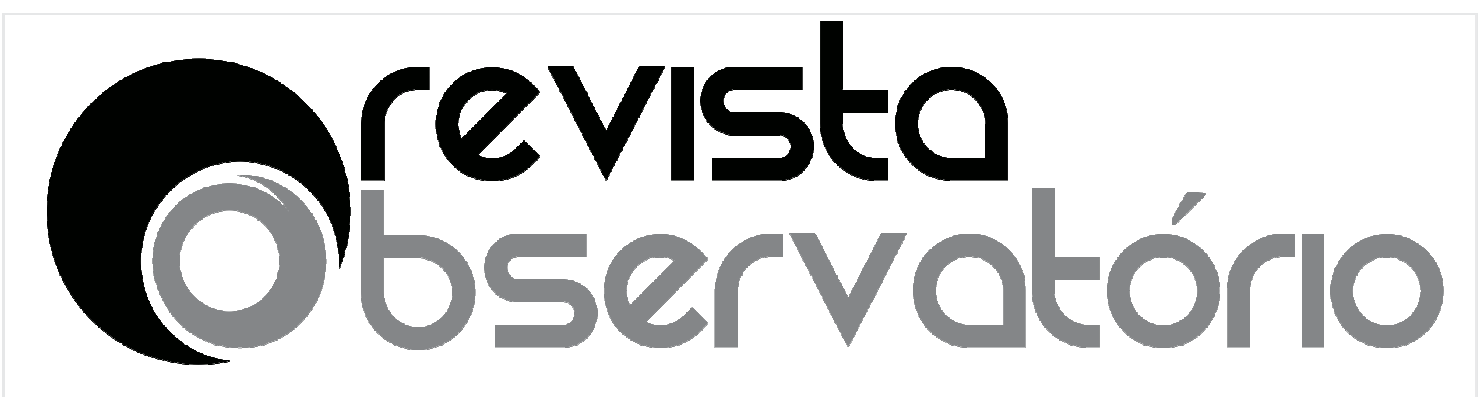

ISSN n² 2447-4266

Vol. 4, n. 2, Abril-Junho. 2018

DOI: http://dx.doi.org/10.20873/uft.2447-4266.2018v4n2p480

MINISTERIO de Educación, http://www.infoleg. gob.ar/ infoleglnternet/anexos/120000-124999/121222/norma.htm (consultado el $15 / 02 / 2014)$

TISSOT, J. (2003); El onanismo. Disertación sobre las enfermedades producidas por la msturbación, Madrid, Asociación Española de Neuropsiquiatría. 